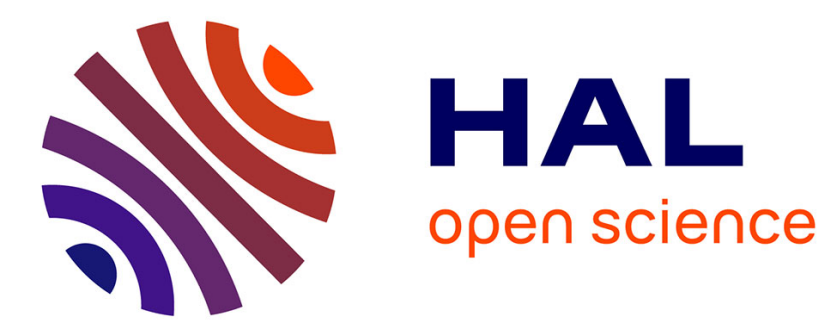

\title{
The horizontal plane appearances of scoliosis: what information can be obtained from top-view images?
}

Tamás S. Illes, Máté Burkus, Szabolcs Somoskeoy, Fabien Lauer, François Lavaste, Jean F. Dubousset

\section{- To cite this version:}

Tamás S. Illes, Máté Burkus, Szabolcs Somoskeoy, Fabien Lauer, François Lavaste, et al.. The horizontal plane appearances of scoliosis: what information can be obtained from top-view images? International Orthopaedics, 2017, 41 (11), pp.2303-2311. 10.1007/s00264-017-3548-5 . hal-01665134

\section{HAL Id: hal-01665134 https://hal.science/hal-01665134}

Submitted on 4 May 2020

HAL is a multi-disciplinary open access archive for the deposit and dissemination of scientific research documents, whether they are published or not. The documents may come from teaching and research institutions in France or abroad, or from public or private research centers.
L'archive ouverte pluridisciplinaire HAL, est destinée au dépôt et à la diffusion de documents scientifiques de niveau recherche, publiés ou non, émanant des établissements d'enseignement et de recherche français ou étrangers, des laboratoires publics ou privés. 


\title{
The horizontal plane appearances of scoliosis: what information can be obtained from top-view images?
}

\author{
Tamás S. Illés ${ }^{1,2,3}$ • Máté Burkus ${ }^{4} \cdot$ Szabolcs Somoskeőy $^{5}$ - Fabien Lauer ${ }^{6}$. \\ Francois Lavaste $^{7} \cdot$ Jean F. Dubousset $^{3}$
}

\begin{abstract}
Purpose A posterior-anterior vertebral vector is proposed to facilitate visualization and understanding of scoliosis. The aim of this study was to highlight the interest of using vertebral vectors, especially in the horizontal plane, in clinical practice. Methods We used an EOS two-/three-dimensional (2D/3D) system and its sterEOS 3D software for 3D reconstruction of 139 normal and 814 scoliotic spines — of which 95 cases were analyzed pre-operatively and post-operatively, as well. Vertebral vectors were generated for each case. Vertebral vectors have starting points in the middle of the interpedicular segment, while they are parallel to the upper plate, ending in the middle of the segment joining the anterior end plates points, thus defining the posterior-anterior axis of vertebrae. To illustrate what information could be obtained from
\end{abstract}

Tamás S. Illés

tamasilles58@yahoo.com

1 Department of Orthopaedics and Traumatology, Brugmann University Hospital, Université Libre de Bruxelles, Place Van Gehuchten 4, 1020 Brussels, Belgium

2 Department of Orthopaedic Surgery and Traumatology, Odense University Hospital and Institute of Clinical Research, University of Southern Denmark, Odense, Denmark

3 National Medical Academy, Paris, France

4 Department of Traumatology and Hand Surgery, Petz Aladár County Teaching Hospital, Győr, Hungary

5 Orthopaedic Department, University Clinical Centre, Pécs University, Pécs, Hungary

6 LORIA, Lorraine Research Laboratory in Computer Science and its Applications, University of Lorraine, Nancy, France

7 Institute of Biomechanics Human Georges Charpak, Arts et Metiers ParisTech, Paris, France vertebral vector-based top-view images, representative cases of a normal spine and a thoracic scoliosis are presented. Results For a normal spine, vector projections in the transverse plane are aligned with the posterior-anterior anatomical axis. For a scoliotic spine, vector projections in the horizontal plane provide information on the lateral decompensation of the spine and the lateral displacement of vertebrae. In the horizontal plane view, vertebral rotation and projections of the sagittal curves can also be analyzed simultaneously. Conclusions The use of posterior-anterior vertebral vector facilitates the understanding of the 3D nature of scoliosis. The approach used is simple. These results are sufficient for a first visual analysis furnishing significant clinical information in all three anatomical planes. This visualization represents a reasonable compromise between mathematical purity and practical use.

Keywords Spine $\cdot$ Scoliosis $\cdot$ Vertebral vector $\cdot$ EOS $\cdot 3 D$ visualisation

\section{Introduction}

Scoliosis is a three-dimensional (3D) spine deformity. Its diagnosis and classification are exclusively based on frontal and lateral X-ray images. Horizontal plane changes have been ignored, even though those rotatory or torsional deformities of the spine are important aspects of scoliosis [1]. Although both lateral curvature and horizontal plane changes seem to increase together in progressive scoliosis, the mechanisms driving vertebral rotation, torsion or lateral translation are not well established. It is unclear whether lateral curvature precedes or is only a consequence of horizontal plane changes [2]. The role and importance of lateral vertebral translation in the 


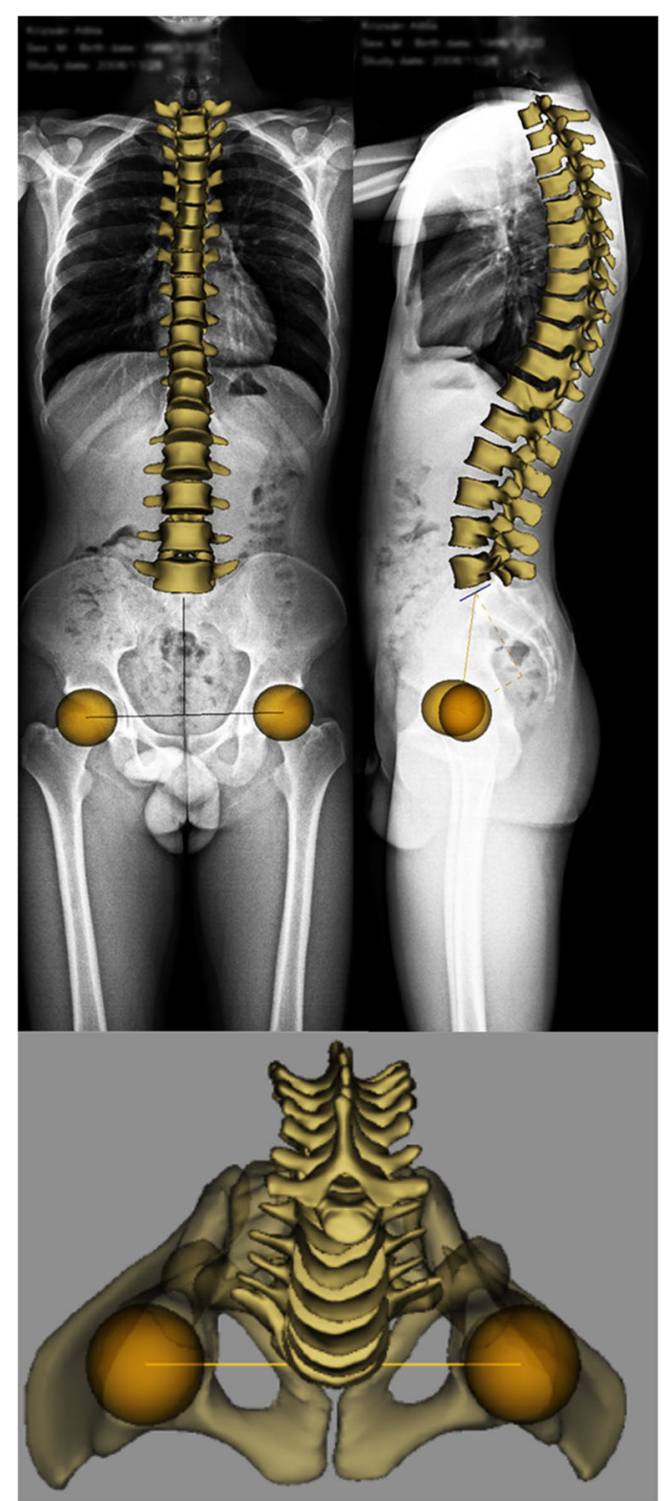

Fig. 1 Three-dimensional reconstruction of a normal spine. AP, lateral and top views

development and progression of scoliosis are even more obscure.

Three-dimensional display of scoliosis can lead understanding its real 3D characteristics, which seemed to be unreachable, despite the extensive researches. One of the main obstacles arose from the difficulties of horizontal plane topview image representation, as we were unable to achieve a clinically useful overhead view demonstration of the deformities. Analysis, evaluation and global display of horizontal positions of vertebrae are a real challenge in clinical practice. Several attempts have been made to visualize and to describe the real 3D appearance of spine deformity $[1,3,4]$, the application of which only slightly improved the limitations of the 3D display [5-7].
The EOSTM 2D/3D system - the low radiation dose orthopedic radio-imaging system based on a Nobel-prize-winning $\mathrm{X}$-ray detection technology - represented a breakthrough in the $3 \mathrm{D}$ visualization of the entire spine, allowing an accurate and realistic 3D reconstruction of the skeletal system, including the spine and pelvis [8].

The vertebral vectors concept has been introduced by our workgroup to visualize and evaluate spinal deformities in a truly 3D manner [9]. A vertebral vector is a replacement for a real vertebra while preserving crucial information for its size, position, orientation and rotation in $3 \mathrm{D}$ projection. Vertebral vectors representing the full spine placed within a coordinate system, based on an individually calibrated scale, provide simple, well-established mathematical ways for evaluation of 3D spinal geometry [10].

The vertebral vector display significantly simplified the simultaneous representation of the spine deformities in all three planes. Its applicability has already been demonstrated in frontal and sagittal planes for both normal and scoliotic spines $[11,12]$. However, the horizontal plane view seems to be the most important because some authors envisage the emergence of scoliosis in this plane [13-15], despite the fact that there is no clear consensus regarding the location of the initial geometry perturbation in scoliosis [16].

With the horizontal plane display, simultaneous 3D analysis of the entire spine becomes available. The horizontal plane view gives us an extended amount of information, which was not able to be derived from anteroposterior (AP) and lateral Xrays in scoliosis. The aims of this study were to highlight the importance of the information obtained from these vertebral vector-based top-view images. To our knowledge, the analysis of deformed spines, displayed by vertebral vectors from an overhead view has not been made yet.

\section{Materials and methods}

The top-view images of a healthy spine selected from 139 examined cases without scoliosis were compared with a surgically treated major right convex thoracic scoliosis chosen from 814 analyzed scoliotic cases, of which 95 cases were also analyzed pre-operatively and post-operatively.

In each case, full-body standing AP and lateral X-rays were simultaneously performed by an EOS 2D/3D system, followed by 3D surface reconstructions with sterEOS software (EOS Imaging, Paris, France). The vertebral reconstruction is based on the determination of stereo-identical points on AP and lateral X-rays. A mathematical algorithm was used on the same points to determine a vector for replacing the vertebrae in an individually calibrated 3D coordinates system. All details of these processes, including the calculations of $3 \mathrm{D}$ vector parameters, were described earlier [9] 
Fig. 2 Three-dimensional reconstructed top view of a normal spine with vertebral vector top-view visualization. In the top view, the vectors are parallel to the $y$-axis and are always perpendicular to the $x$-axis. It is a natural phenomenon when the vertebrae do not have an axial rotation. The sensitivity of this visualization is visible since a small axial rotation is already detectable that has no radiological or clinical signs
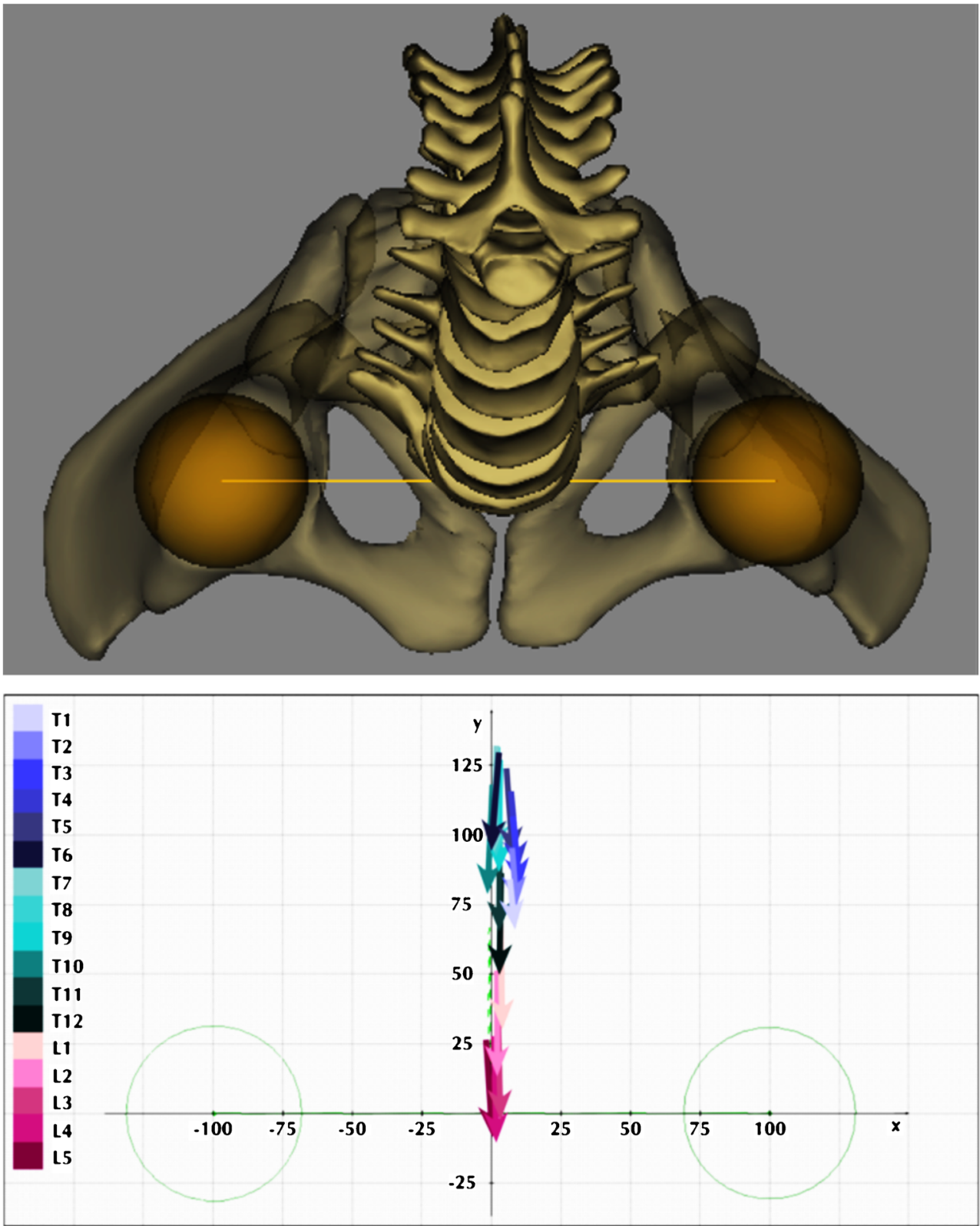

$d_{u c}=186.6 \mathrm{~mm}, d_{u c s 0}=93.3 \mathrm{~mm}$

échelle du système de coordonnées $=100: 93.3 \mathrm{~mm}$
This study was focused only on the horizontal plane vertebral vector projection. Thus, we only used the $x, y$ parameters of the start and end points $(A x, A y, B x, B y)$ of the vertebral vectors. After measuring the interacetabular center's distance, the real values of the starting and end points of vertebral vectors from the $x$-axis $(d x)$ and the $y$-axis $(d y)$ was calculated in millimeters (mm) using the following formulae:

$$
\left(d x=A x \frac{\frac{\text { interacetabular distance }(\mathrm{mm})}{2}}{100}\right) ;\left(d y=A y \frac{\frac{\text { interacetabular distance }(\mathrm{mm})}{2}}{100}\right) .
$$

The trigonometrical tangent function

$$
\left(\operatorname{tg} a=\frac{(B x-A x)}{(B y-A y)}\right)
$$

has also been used to determine in the horizontal plane the projected axial rotations.

\section{Results}

The 3D reconstructions of the normal spine without pathological lateral curvature are shown in Fig. 1. The 3D top view and 
Table 1 Vertebral vector parameters of a normal spine with the real distances calculated from the respective axis

\begin{tabular}{|c|c|c|c|c|c|c|c|c|c|}
\hline & $A x$ & $\mathrm{~mm}$ & $B x$ & $\mathrm{~mm}$ & $A y$ & $\mathrm{~mm}$ & By & $\mathrm{mm}$ & Degrees \\
\hline T 1 & 6.4 & 6.0 & 8.3 & 7.8 & 84.3 & 78.7 & 64.5 & 60.2 & 2.2 \\
\hline Т 2 & 7.1 & 6.6 & 9.1 & 8.4 & 95.8 & 89.3 & 71.8 & 67.0 & 0.8 \\
\hline Т 3 & 7.7 & 7.2 & 10.5 & 9.8 & 106.6 & 99.4 & 78.2 & 73.0 & -0.1 \\
\hline T 4 & 7.0 & 6.6 & 10.0 & 9.3 & 116.0 & 108.3 & 85.1 & 79.4 & -3.4 \\
\hline T 5 & 5.4 & 5.0 & 7.7 & 7.1 & 124.3 & 116.0 & 91.3 & 85.2 & -3.1 \\
\hline Т 6 & 2.9 & 2.7 & 0.0 & 0.0 & 130.0 & 121.3 & 93.9 & 87.6 & -2.4 \\
\hline T 7 & 1.7 & 1.6 & 0.5 & 0.5 & 132.4 & 123.6 & 93.5 & 87.3 & -0.7 \\
\hline T 8 & 2.1 & 2.0 & 1.5 & 1.4 & 132.0 & 123.1 & 91.7 & 85.5 & 2.3 \\
\hline Т 9 & 3.1 & 2.9 & 2.4 & 2.3 & 127.3 & 118.8 & 86.2 & 80.4 & 0.2 \\
\hline T 10 & 0.3 & 0.3 & -1.6 & -1.5 & 118.3 & 110.4 & 77.7 & 72.5 & 1.7 \\
\hline T 11 & 3.2 & 3.0 & 2.5 & 2.3 & 104.2 & 97.3 & 63.9 & 59.6 & 1.2 \\
\hline T 12 & 3.1 & 2.9 & 2.1 & 1.9 & 86.4 & 80.6 & 44.7 & 41.7 & 3.2 \\
\hline L 1 & 2.6 & 2.5 & 3.3 & 3.1 & 69.2 & 64.6 & 27.9 & 26.0 & 0.6 \\
\hline L 2 & 1.7 & 1.6 & 1.5 & 1.4 & 51.6 & 48.1 & 11.6 & 10.8 & 2.0 \\
\hline L 3 & 2.0 & 1.8 & 2.8 & 2.7 & 38.4 & 35.8 & -3.4 & -3.2 & -0.7 \\
\hline L 4 & 0.8 & 0.8 & 1.6 & 1.5 & 28.0 & 26.1 & -10.6 & -9.9 & -2.1 \\
\hline L 5 & -2.1 & -2.0 & 0.1 & 0.1 & 26.2 & 24.4 & -9.0 & -8.4 & -2.1 \\
\hline
\end{tabular}

the generated vertebral vectors are shown in Fig. 2. After replacing the vertebrae with vectors, their appearance and orientation could be analyzed in the horizontal plane. The vertebral vector coordinates of the starting and end points of each vertebra, the projected distances in $\mathrm{mm}(d)$ from the same points and the projected axial vertebral rotation are shown in Table 1.

The $x$ coordinates represent the distance from the $y$-axis, while the $y$ coordinates represent the range from the $x$-axis. The $x$ coordinates of the starting and end points of vertebral vectors are close to each other (Table 1 , rows $T 2$ and T4). Therefore their distances from the $y$-axis are approximately the same (Table 1, $\mathrm{mm}$ columns 3 and 5). Consequently, the projected values of axial rotation are minimal (Table 1, Degrees column).

The $y$ values of starting and end points (Table 1, columns $A y$ and $B y$ ) are continuously increased to the $\mathrm{T} 7$ vertebra and then decreased similarly to the T11 vertebra. Based on this observation, the apical vertebra of thoracic kyphosis was the seventh thoracic vertebra. Distance from the $x$-axis is also constantly growing to the $\mathrm{T} 7$ vertebra, which was positioned about $12 \mathrm{~cm}$ posteriorly, while the T1 vertebra was only $7 \mathrm{~cm}$ positioned posteriorly (Table 1, $\mathrm{mm}$ columns 7 and 9). This positioning of the vertebrae in this localization is the sign of significant thoracic kyphosis.

Pre-operative and post-operative AP and lateral 3D reconstruction of a 15-year-old right convex severe thoracic scoliotic girl were visualized in Fig. 3a-d with pre-operative and post-operative 3D top view image (Fig. 3e, f). The top view 3D images are also shown in Fig. 4a, b with the visualization by vertebral vectors (Fig. 4c, d.
Real distance from the $x$ - and $y$-axes (pre-operative and post-operative vector coordinates) calculated from the interacetabular distance, and the projected axial vertebral rotation, are shown in Tables 2 and 3 and were analyzed in the same manner as a normal spine.

On the 3D top view, only the trends of the corrections can be judged. After visualizing the whole spine with vertebra vectors, it is possible to analyze the deformity carefully.

Before surgery, the vertebral vectors were arranged close to the $x$-axis (Table 2, columns $A y$ and By; Fig. 4c). The vertebrae are situated near and mainly above the interacetabular axis (Fig. 4a). The projection distance between the two furthest vertebrae is only $55 \mathrm{~mm}$ (Table 2, rows $T 7$ and $T 9$ ), of which the T6 vertebra is located behind, while the L4 vertebra is found in front of the interacetabular axis (Fig. 4a, c).

The T1 vertebra displaced from the $y$-axis by $2.5 \mathrm{~cm}$ to the right with $16^{\circ}$ projected axial rotation (Fig. 4a, c; Table 2, row T1/mm columns 3, 5, and Degrees). The most laterally displaced vertebra is the T9 with $9 \mathrm{~cm}$ distance from the $y$ axis. This lateral displacement is accompanied by $31^{\circ}$ projected axial rotation (Fig. 4a, c; Table 2, row T9/mm columns 3, 5, and Degrees). The last four lumbar vertebrae are situated near the $y$-axis without significant projected axial rotation (Fig. 4a, c; Table 2, rows L2-L5/mm columns 3, 5, and Degrees). Except for the L5 vertebra, which has $14^{\circ}$ projected axial rotation (Fig. 4a, c; Table 2, row L5/Degrees column). The spine is not only flat but also decompensated to the right side.

After surgery, the vertebrae arranged next to the $y$-axis. The distances to the extreme right T4 (Fig. 4b, d; Table 3, row T4/ $m m$ columns 3 and 5) and the extreme left T10 (Fig. 4b, d; Table 3, row T10/mm columns 3 and 5). Vertebrae from the $y$ axis are the same 13 and $14.3 \mathrm{~mm}$, respectively (Fig. 4b, d; Table 3, row T9/columns mm 3, 5, and Degrees). Each vertebral vector is situated between these two vertebral vectors.

The $y$ coordinates of each thoracic vertebra increased considerably (Table 3, columns $A y$ and $B y$ ) compared with the preoperative value, which is the sign that the vertebrae are moved away from the $x$-axis (Table 3, mm columns 7 and 9). The most posteriorly positioned vertebra is the T7, with $46.5 \mathrm{~mm}$ distance from the interacetabular axis. From this vertebra, the $y$ coordinates of the vertebral vector starting points decrease to L3 vertebra then increase again (Table 3, Ay column).

The projected axial rotations of each vertebra are diminished (Table 3, row $T 9$ ) during surgery compared with preoperative values (Table 2, Degrees column), except the T1 vertebra, which did not change in rotation.

\section{Discussion}

With scoliosis being a 3D spinal deformity, there is a high demand for visualizing the curves in all three planes, 


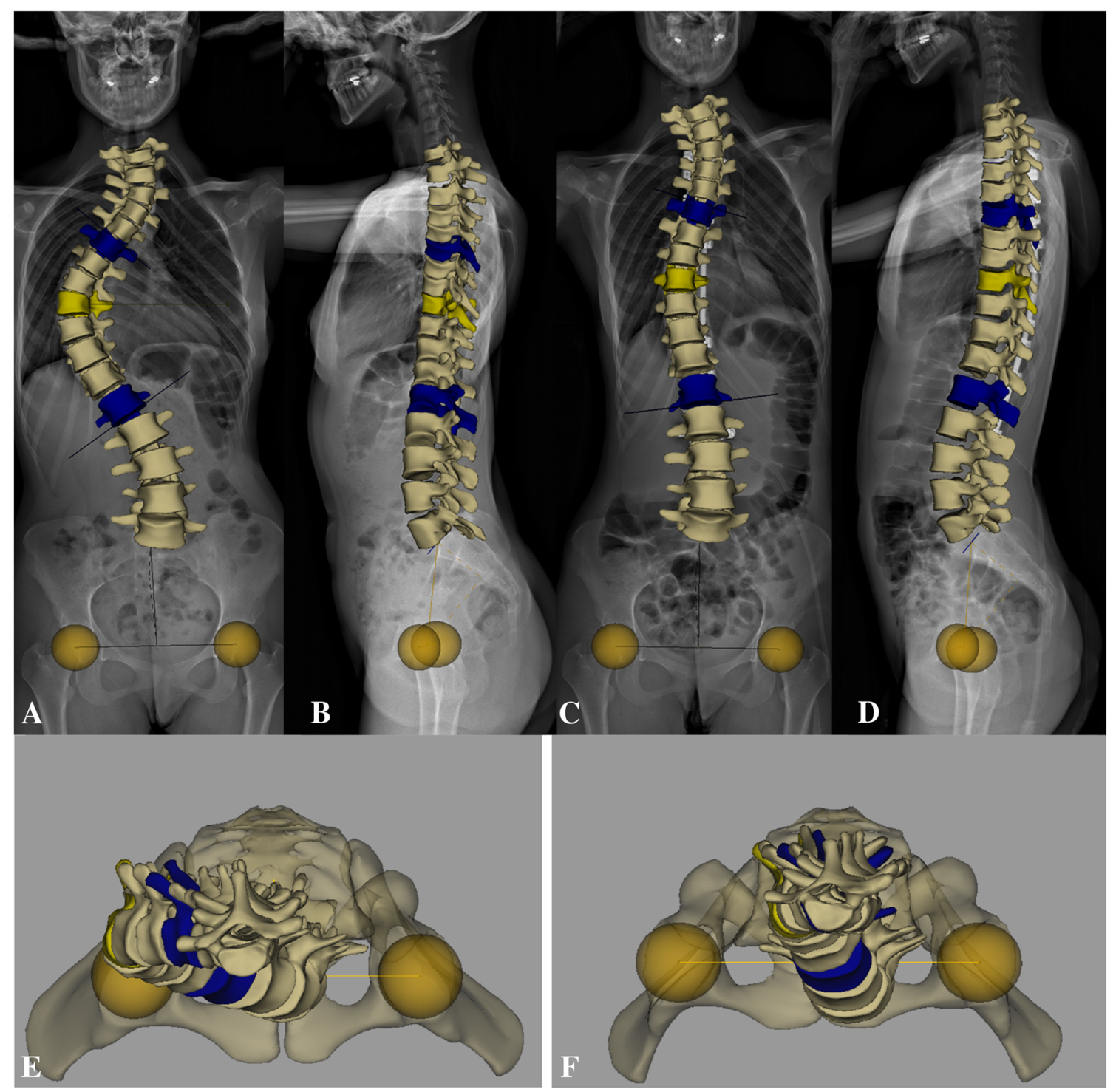

Fig. 3 Pre-operative and post-operative 3D reconstruction of a thoracic right convex scoliosis. AP, lateral and top views

especially in the horizontal plane. The most accurate assessment of horizontal plane alterations seems to be achieved by computed tomography (CT). However, it is limited in routine scoliosis diagnosis, due to high radiation dose, short examinable spinal segments and the effect of supine position, which may lead to significant alterations of the curves [17].

The DaVinci representation visualizing a top view through the plane of maximum curvature (PMC) was introduced and thought to make a $3 \mathrm{D}$ evaluation of idiopathic scoliosis readily available for routine clinical practice [18]. The PMC is an abstract, continually changing, extraspinal auxiliary plane determined by the apical and the two end vertebrae. It is difficult to understand, laborious to reproduce and difficult to explain its clinical significance of daily practice. Although there is an association between the severity of scoliosis and the PMC, the greatest correlation is associated only with the sagittal curvature [19].
The most accurate 3D visualization of the whole spine is based on the new EOS 2D/3D pictures allowing simultaneous, upright, perpendicular coronal and lateral X-ray capture of full-body in a spatially calibrated way. The highquality EOS images allow very accurate $3 \mathrm{D}$ surface reconstruction using sterEOS 3D software [20, 21]. In biomechanics, 3D angular positions of the vertebrae of a scoliotic spine are conventionally obtained by calculating three angles using the method of the movable axes (3D Bryant angles). The sterEOS 3D software calculates the $3 \mathrm{D}$ angles the same way, which is a precise mathematical definition [22]. However, its interpretation in clinical practice is very challenging due to its difficult interpretation. Therefore, an error often committed in clinical practice is calling these $3 \mathrm{D}$ angles as angles in the frontal, sagittal or transverse plane, thus confusing it with the angles projected into the anatomical planes. 


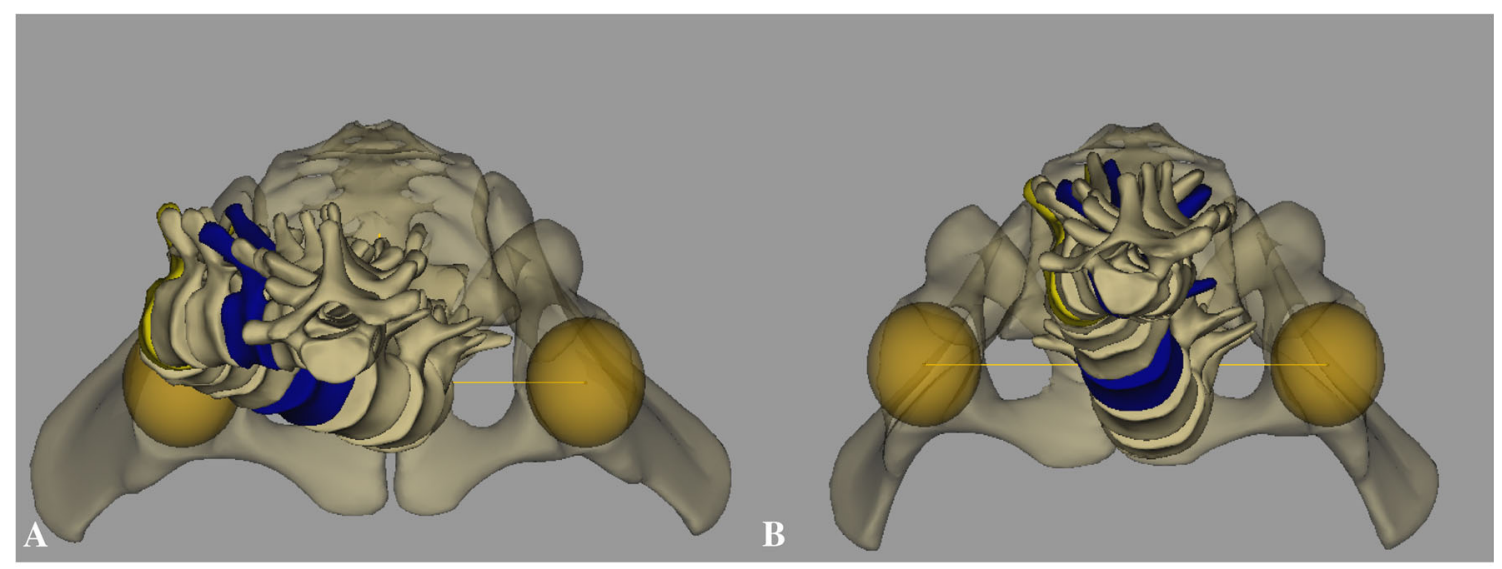

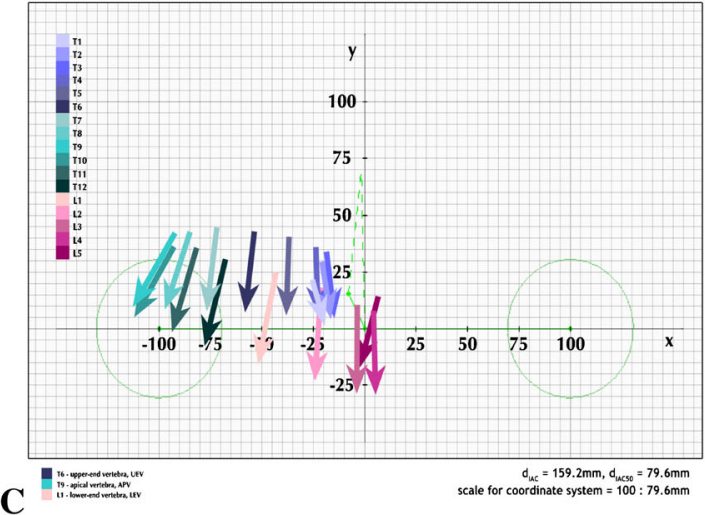

Fig. 4 3D reconstructed top views with top-view visualizations by vertebral vectors. On $3 \mathrm{D}$ top view only, the trends of the corrections can be judged $(\mathbf{a}, \mathbf{b})$. After visualizing the whole spine with vertebral vectors, a lot of information can be obtained from the top-view images. Before surgery, the vertebrae arranged near the $x$-axis indicating the decrease of the sagittal curves. Each vertebra is displaced laterally from the $y$-axis, so the spine is not only flat but decompensated to the right side also (c).

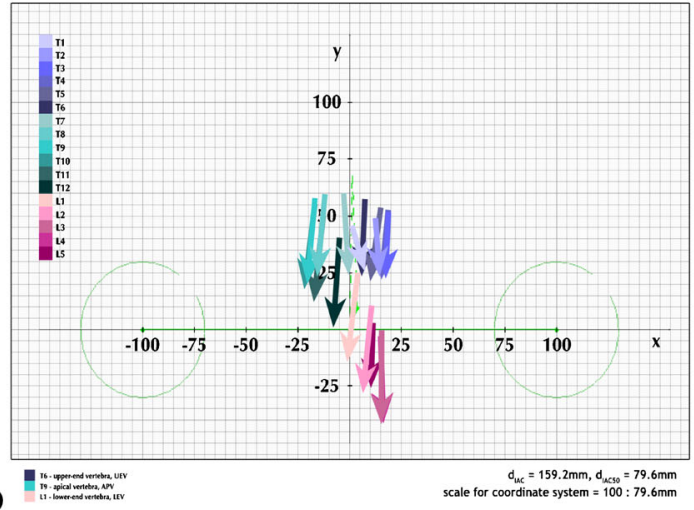

During the surgery, the thoracic vertebrae moved away from the $x$-axis and arranged next to the $y$-axis. With these movements, the sagittal curves became harmonic. The distances to the extreme right and the extreme left vertebrae from the $y$-axis are the same, while each vertebral vector situates between these two vertebrae, the spine became compensated, in spite of the residual curves. The pre-operative significant apical vertebra's axial rotation also decreased during surgery $(\mathbf{d})$
In clinical practice, the most frequently used angles are the ones projected on the reference anatomical planes that correspond to the angles visible on frontal and lateral X-rays and have clinical meaning.

The posterior-anterior vertebral vector projection in three different planes facilitate the 3D visualization of the deformations [9]. Using an individually calibrated coordinate system, the evaluation of all vertebral vector coordinates is possible, allowing mathematical analysis of projected vertebral position for each vertebra in all three planes. The usefulness of vertebral vectors in the description of scoliosis is already proved [11]. We limit ourselves in this study to the horizontal plane visualization of the posterior-anterior vertebral vector.

For intact vertebral columns in the horizontal plane, the vectors are aligned with the posteroanterior anatomical axis. In this case, the $x$-coordinates of starting ( $A x)$ and end-points $(B x)$ of the vectors are nearly identical and approaching zero. In this case, the vertebral bodies are aligned with the caudocranial anatomical axis without significant axial rotation, which is the normal condition when the spine has no lateral curvature.

The $y$ coordinates of the vector origins are proportional to the measured distance from the $x$-axis. On this basis, it is possible to estimate the magnitude of the sagittal curves. Of course, further studies are needed to determine the exact relationship between the magnitude of the sagittal curves and the projected values of vertebral vectors in the horizontal plane.

In scoliosis, the same posterior-anterior projection of the vertebral vector does not coincide with the anatomical axis of the body. In the horizontal plane, the projections of the origin of the vectors provide information on the lateral deviation. The magnitude of the curve is directly proportional to the $x$ coordinates of the apical vertebral vector. Based solely on the horizontal view, it is also possible to deduce the upper body decompensation. Where the T1 vertebra $x$ coordinates are not zero or close to zero, the upper body is decompensated. The higher the $x$ coordinate of $\mathrm{T} 1$, the greater is the decompensation. The real decompensation is equal to the actual distance 
Table 2 Pre-operative vector coordinates of thoracic scoliosis with the real distances calculated from the respective axis

\begin{tabular}{|c|c|c|c|c|c|c|c|c|c|}
\hline & $A x$ & $\mathrm{~mm}$ & $B x$ & $\mathrm{~mm}$ & $A y$ & $\mathrm{~mm}$ & $B y$ & $\mathrm{~mm}$ & Degrees \\
\hline T 1 & -25.3 & -24.5 & -19.4 & -18.6 & 21.6 & 17.2 & 1.4 & 1.1 & 16.2 \\
\hline Т 2 & -20.6 & -19.8 & -16.7 & -15.9 & 29.7 & 23.6 & 3.9 & 3.1 & 8.7 \\
\hline Т 3 & -18.3 & -17.5 & -14.5 & -13.7 & 33.9 & 27.0 & 5.0 & 4.0 & 7.5 \\
\hline $\mathrm{T} 4$ & -23.5 & -22.7 & -21.5 & -20.7 & 36.4 & 28.9 & 5.4 & 4.3 & 3.6 \\
\hline Т 5 & -36.4 & -35.6 & -37.6 & -36.8 & 40.4 & 32.1 & 5.9 & 4.7 & -2.0 \\
\hline Т 6 & -53.4 & -52.6 & -57.8 & -57.0 & 42.6 & 33.9 & 7.2 & 5.7 & -7.2 \\
\hline Т 7 & -70.8 & -70.0 & -75.6 & -74.9 & 43.9 & 35.0 & 7.7 & 6.1 & -7.7 \\
\hline Т 8 & -84.4 & -83.6 & -97.0 & -96.2 & 42.4 & 33.8 & 8.3 & 6.6 & -20.2 \\
\hline Т 9 & -91.1 & -90.3 & -110.5 & -109.7 & 41.7 & 33.2 & 9.7 & 7.7 & -31.1 \\
\hline Т 10 & -91.9 & -91.1 & -109.4 & -108.6 & 35.7 & 28.4 & 3.5 & 2.8 & -28.4 \\
\hline Т 11 & -82.7 & -82.0 & -94.4 & -93.6 & 35.7 & 28.5 & -0.8 & -0.7 & -17.7 \\
\hline Т 12 & -65.9 & -65.1 & -74.3 & -73.5 & 30.4 & 24.2 & -8.4 & -6.7 & -12.3 \\
\hline L 1 & -42.7 & -41.9 & -49.9 & -49.1 & 24.8 & 19.7 & -15.9 & -12.7 & -10.0 \\
\hline L 2 & -20.9 & -20.1 & -22.7 & -21.9 & 18.3 & 14.6 & -23.0 & -18.3 & -2.5 \\
\hline L 3 & -3.7 & -2.9 & -3.9 & -3.1 & 10.6 & 8.4 & -28.3 & -22.5 & -0.3 \\
\hline L 4 & 4.6 & 5.4 & 5.1 & 5.9 & 8.5 & 6.7 & -29.6 & -23.5 & 0.8 \\
\hline L 5 & 5.9 & 6.7 & -2.2 & -1.4 & 15.3 & 12.2 & -15.7 & -12.5 & -14.7 \\
\hline
\end{tabular}

from the $y$-axis, calculated from the vector coordinates. However, if the distances to the extreme right and the extreme left vertebrae from the $y$-axis are the same, the spine should be considered compensated, despite any residual curvatures. In this case, the spine is situated in the "economical" or smooth cone when the muscles are working at their minimum to maintain balance [23].
The direction vectors depict the axial rotation of the vertebrae. The projected value of vertebral rotation can be calculated by the trigonometry tangent function using the $x$ coordinates of the starting and end points of the vertebral vectors.

In the horizontal plane, the vertebral vectors allow a proper assessment of the situation of the column without using axillary plans (like PMC) and provide useful information in daily

Table 3 Post-operative vector coordinates of thoracic scoliosis with the real distances calculated from the respective axis and axial rotation of each vertebral vectors

\begin{tabular}{|c|c|c|c|c|c|c|c|c|c|}
\hline & $A x$ & $\mathrm{~mm}$ & $B x$ & $\mathrm{~mm}$ & $A y$ & $\mathrm{~mm}$ & $B y$ & $\mathrm{~mm}$ & Degrees \\
\hline T 1 & -0.2 & -0.2 & 5.6 & 4.5 & 44.1 & 35.1 & 24.6 & 19.6 & 16.6 \\
\hline Т 2 & 10.7 & 8.5 & 13.2 & 10.5 & 47.7 & 38.0 & 22.5 & 17.9 & 5.8 \\
\hline Т 3 & 16.2 & 12.9 & 15.9 & 12.6 & 50.5 & 40.2 & 22.0 & 17.5 & -0.7 \\
\hline $\mathrm{T} 4$ & 16.4 & 13.0 & 13.9 & 11.1 & 51.4 & 40.9 & 21.5 & 17.1 & -4.7 \\
\hline Т 5 & 13.1 & 10.4 & 8.3 & 6.6 & 52.3 & 41.6 & 20.7 & 16.5 & -8.7 \\
\hline Т 6 & 5.5 & 4.4 & 4.3 & 3.4 & 55.7 & 44.3 & 22.4 & 17.9 & -2.1 \\
\hline Т 7 & -5.1 & -4.0 & -2.7 & -2.2 & 58.4 & 46.5 & 23.0 & 18.3 & 3.8 \\
\hline Т 8 & -13.5 & -10.7 & -16.5 & -13.1 & 57.8 & 46.0 & 22.4 & 17.9 & -4.9 \\
\hline Т 9 & -17.9 & -14.2 & -20.5 & -16.3 & 56.2 & 44.7 & 20.3 & 16.2 & -4.2 \\
\hline Т 10 & -17.9 & -14.3 & -22.9 & -18.3 & 53.6 & 42.6 & 17.6 & 14.0 & -7.9 \\
\hline Т 11 & -13.3 & -10.6 & -18.1 & -14.4 & 48.3 & 38.4 & 11.2 & 8.9 & -7.2 \\
\hline Т 12 & -6.0 & -4.8 & -9.0 & -7.2 & 38.9 & 30.9 & 0.5 & 0.4 & -4.4 \\
\hline L 1 & 2.1 & 1.7 & -2.4 & -1.9 & 24.5 & 19.5 & -14.0 & -11.1 & -6.7 \\
\hline L 2 & 8.8 & 7.0 & 5.0 & 4.0 & 10.1 & 8.1 & -27.4 & -21.8 & -5.8 \\
\hline L 3 & 13.2 & 10.5 & 13.3 & 10.6 & -0.2 & -0.2 & -38.9 & -31.0 & 0.2 \\
\hline L 4 & 13.5 & 10.8 & 14.9 & 11.9 & -2.6 & -2.1 & -40.2 & -32.0 & 2.1 \\
\hline L 5 & 9.9 & 7.9 & 9.3 & 7.4 & 2.6 & 2.1 & -27.9 & -22.2 & -1.2 \\
\hline
\end{tabular}


clinical practice before and after surgery. It shows the exact location and the relationship of the frontal and sagittal curves of the vertebral rotation in the lateral displacement of the vertebrae. This view stimulates the surgeons to carry out his correction by trying to be as close as possible to the balance of the spine. To achieve a balanced spine, the translation will be the principal manoeuvre of surgery for minimizing the lateral ejection of vertebrae [10]. To perform the translation, it is not necessary to use screws in every segment. In a case of thoracic lordosis - when vertebral vectors regroup near to the $x$-axis-, while forcing the thoracic segment to recreate the kyphotic curve, it is also necessary to avoid using screws everywhere since they act against kyphosis [24].

In post-operative top view, we can see at a glance the situation obtained with an overall 3D balance. Occasionally a residual imbalance may be present that we will be able to control and measure during the follow-up.

By using vertebral vector-based top-view images alone, all factors playing a role in the appearance of scoliosis (vertebral rotation, lateral displacement, frontal and sagittal curves) can be visualized and analyzed in parallel. Projections of vertebral vectors in other planes may supplement this information, but some projections are overabundant. In everyday clinical practice, we use these top views in pre-operative planning and evaluation of the effectiveness of surgical correction because this visualization is now an integrated part of sterEOS software. Horizontal representation with the vertebral vectors provides access to viewing for the better understanding of $3 \mathrm{D}$ scoliosis. Angular encrypted data from the 3D reconstruction allow rigorous quantitative analysis of the deformation, but can independently bias projection. These two components, one visual and one quantitative, complement for a better understanding of scoliotic deformities.

\section{Conclusions}

The posterior-anterior vertebral vector in the horizontal plane facilitates the understanding of the 3D nature of scoliosis. The approach used is simple. These results are sufficient for a first visual analysis, providing significant clinical information in the three anatomical planes. This visuali zation approach represents a reasonable compromise between mathematical purity and practical use.

\section{References}

1. Graf H, Hecquet J, Dubousset J (1983) Approche tridimensionnelle des déformations rachidiennes: application à l'étude du pronostic des scolioses infantiles. Rev Chir Orthop 69:407-416
2. Stokes IA, Gardner-Morse M (1991) Analysis of the interaction between vertebral lateral deviation and axial rotation in scoliosis. J Biomech 24:753-759

3. De Smet AA, Tarlton MA, Cook LT, Berrigr AS, Asher M (1983) The top view for analysis of scoliosis progression. Radiology 2: 369-372

4. Howell FR, Dickson RA (1989) The deformity of idiopathic scoliosis made visible by computer graphics. J Bone Joint Surg Br 71: 399-403

5. Gardner-Morse M, Stokes IA (1994) Three-dimensional simulations of the scoliosis derotation maneuver with Cotrel-Dubousset instrumentation. J Biomech 27(2):177-181

6. Kojima T, Kurokawa T (1992) Rotation vector, a new method for representation of three-dimensional deformity in scoliosis. Spine 17:1296-1303

7. Stokes IA, Gardner-Morse M (1993) Three-dimensional simulation of Harrington distraction instrumentation for surgical correction of scoliosis. Spine 18:2457-2464

8. Dubousset J, Charpak G, Dorion I et al (2005) A new 2D and 3D imaging approach to musculoskeletal physiology and pathology with low-dose radiation and the standing position: the EOS system. Bull Acad Natl Med 189:287-297

9. Illés T, Tunyogi-Csapó M, Somoskeöy S (2011) Breakthrough in three-dimensional scoliosis diagnosis - significance of horizontal plane view and vertebra vectors. Eur Spine J 20:135-143

10. Illés T, Somoskeőy S (2013) Comparison of scoliosis measurements based on three-dimensional vertebra vectors and conventional two-dimensional measurements: advantages in evaluation of prognosis and surgical results. Eur Spine J 22:1255-1263

11. Somoskeöy S, Tunyogi-Csapó M, Bogyó C, Illés T (2012) Clinical validation of coronal and sagittal spinal curve measurements based on three-dimensional vertebra vector parameters. Spine J 12:960968

12. Somoskeöy S, Tunyogi-Csapó M, Bogyó C, Illés T (2012) Accuracy and reliability of coronal and sagittal spinal curvature data based on patient-specific three-dimensional models created by the EOS 2D/3D imaging system. Spine J 12:1052-1059

13. Sevastik JA, Aaro S, Normelli H (1984) Scoliosis. Experimental and clinical studies. Clin Orthop 191:27-34

14. Perdriolle R, Vidal J (1987) Morphology of scoliosis: threedimensional evolution. Orthopaedics 10:909-915

15. Burwell RG, Cole AA, Cook TA et al (1992) Pathogenesis of idiopathic scoliosis: the Nottingham concept. Acta Orthop Belg 58(S): 33-58

16. Pope MH, Stokes IA, Moreland M (1984) The biomechanics of scoliosis. Crit Rev Biomed Eng 11:157-188

17. Yazici M, Acaroglu ER, Alanay A et al (2001) Measurement of vertebral rotation in standing versus supine position in adolescent idiopathic scoliosis. J Pediatr Orthop 21:252-256

18. Sangole AP, Aubin C-E, Labelle H et al (2009) Three-dimensional classification of thoracic scoliotic curves. Spine 34:91-99

19. Villemure I, Aubin C-E, Grimard G, Dansereau J, Labelle H (2001) Progression of vertebral and spinal three-dimensional deformities in adolescent idiopathic scoliosis: a longitudinal study. Spine 26: 2244-2250

20. Le Bras A, Laporte S, Mitton D et al (2002) 3D detailed reconstruction of vertebrae with low dose digital stereoradiography. Stud Health Technol Inform 91:286-290

21. Le Bras A, Laporte S, Mitton D et al (2003) A biplanar reconstruction method based on 2D and 3D contours: application to the distal femur. Comput Methods Biomech Biomed Engin 6:1-6

22. Skalli W, Lavaste F, Descrimes JL (1995) Quantification of threedimensional vertebral rotations in scoliosis: what are the true values? Spine 20:546-553 
23. Dubousset J (1994) Three-dimensional analysis of the scoliotic deformity. In: Weinstein SL (ed) The pediatric spine: principles and practice. Raven Press, New York, pp 479-496
24. Blondel B, Lafage V, Schwab F et al (2012) Reciprocal sagittal alignment changes after posterior fusion in the setting of adolescent idiopathic scoliosis. Eur Spine J 21:1964-1971 